\title{
Analysis of Resource-use Efficiency and Productivity of Residual Soil Moisture Tomato Production in Kaduna State, Nigeria
}

\author{
A. S. S. Umar ${ }^{1, *}$, M. B. Abdulkadir ${ }^{2}$ \\ ${ }^{1}$ Department of Agricultural Economics, University of Maiduguri, \\ P.M.B.1069, Maiduguri, Borno State, Nigeria \\ ${ }^{2}$ Federal ministry of Agriculture, Livestock Division, Abuja, Nigeria \\ *E-mail address: sidiumar@yahoo.com
}

Keywords: Residual Soil; Tomato Production in Kaduna State

\begin{abstract}
This study was conducted to examine the resource-use efficiency and productivity of residual soil moisture tomato production Kaduna state, Nigeria. Descriptive statistics and production function analysis were used to analyze the data. The result showed that the production function analysis showed that $54.55 \%$ of the residual soil moisture tomato yields among the sampled farmers were explained by the specified inputs. The coefficients of land and labour, and Seed/seedlings significantly influence the output of residual soil moisture of tomato production. Similarly, land and seed were under-utilized, while labour is the most was over used. To improve the efficiency of inputs used, the study recommends that farmer's access to modern technologies should be enhance, there should be effective and efficient extension service, easy access to formal credit facilities and also encourage them to form cooperative societies to enable them procure their inputs at reduce rate.
\end{abstract}

\section{INTRODUCTION}

The production and consumption of vegetable is increasingly gaining popularity in Nigeria recently. This is probably due to public awareness and concern about health safety. Emphasis is being placed on the quality and safety of the food consumed which is mostly associated with vegetables. Vegetables are considered as the most nourishing food because they contain little of all the essential nutrients required for health living (Ibekwe and Adesope, 2010).

Tomato is the one of the vegetable commonly cultivated in most part of the world, ranking second only to potatoes in production (Ojo et al., 2009). It is an important ingredient in the diet of most people in the nation. It can be eaten raw or cooked. They are used in the preparation of soup, juice and sauces, ketchups, purees and paste (Haruna, et al., 2012). They are particular is indispensible to attainment of balanced nutrition in the diet of the average people. Tomato is one of the best and principal sources of vitamins which are not present in most other foods in sufficient quantities to meet the requirement of the body. It is beneficial for the maintenance of good health and disease prevention (Usman and Bakari, 2013). It is very important source of vitamins and minerals essential for healthy human diet (Ojo, et al. 2009).

Tomato is cultivated in most part of the nation. However, northern Nigeria accounts for the bulk of the tomatoes produced in the nation. The leading tomato producing States in the nations include Kaduna, Kano, Borno, Plateau Sokoto, Jigawa and Yobe. Tomato is mainly produce by resource poor small farmers with small farm holdings. They are responsible for the tomato consume in the nation (Adenegan and Adeoye, 2011).

Nigeria was ranked second highest producer of tomato in Africa and thirtieth leading producer in the World, producing 1.701 million tonnes of tomato annually at an average of 25- 30 per hectare (FAO, 2010). However, the average yield of the crop is far below the potential of the crop. For instance, the average yield about 6 tonnes is much lower than 7 tonnes and 6.48 tonnes reported for Tanzania and Uganda respectively. The low level of productivity could be attributed to inefficient use of resources (Mbanasor and Kalu, 2008). 
Improving the resource-use efficiency is most important means of increasing the output of the products especially for poor farmers who are responsible for the bulk of the consumed in the nation (Goni, et al. 2013). In a resource poor country like Nigeria, improving the efficiency of inputs-use is of paramount importance. The scope of agricultural production can be expanded and sustained through the efficient use of resources given the existing resource base and available technology. This is particularly true of the poverty stricken economies where resources are meager and opportunities for developing and adopting better technologies are dwindling (Udoh, 2005). An input is said to be efficiently utilized when it is put to the best possible use at the lowest possible cost and quantity (Tambo and Theresa, 2010).

It is necessary to investigate the existing level of resource-use efficiency with a view to determine the factors responsible for this level of efficiency with a view to further improve the level of productivity. There is dearth of literature on the efficiency of resource-use of residual soil moisture tomato production in Kaduna state. Hence, this study was conducted to determine the efficiency of resource-use efficiency and estimate the production function of the residual soil moisture tomato production condition in Kaduna State

\section{Objectives of the Study}

The main objective of this study is to determine the efficiency of resource-use in residual soil moisture tomato production condition in Kaduna, Nigeria. The specific objectives of the study are to:

i. determine the efficiency of resource-use efficiency of residual soil moisture tomato production in the study area and

ii. estimate the production function of the residual soil moisture tomato production in the study area.

\section{MATERIALS AND METHOD}

\subsection{The Study Area}

The Kaduna State is located between latitudes $10^{\circ} 20^{\prime} \mathrm{N}$ and longitudes $7^{\circ} 45^{\prime} \mathrm{E}$ of the prime meridian. It has an average altitude of $640 \mathrm{~m}$ above sea level. It has a population of $6,066,562$ people and is the third largest in the federation after Lagos and Kano (NPC, 2006). There is climatic variation between the northern and the southern parts of the state. The northern part, where the study area lies, fell within the Northern Guinea savanna type of vegetation. It has two distinct wet and dry seasons. The wet season spans within the months of April to October and a dry season between November and March. The mean annual rainfall is $1164 \mathrm{~mm}$ and reaches its peak in August. The annual temperature ranges from $27.2-36.3^{\circ} \mathrm{C}$. The relative humidity is similarly variable, averaging between $15-25 \%$ in dry season and rising to between $48-84$ percent in wet season. The area has a well-drained ferruginous tropical soil which is sandy clay to clay loam in texture.

The people are predominantly farmers. The main crops cultivated are maize, rice, cowpea and vegetables particularly tomato, pepper, cabbage, mango, guava and cashew nut. Livestock commonly kept include cattle sheep goat and poultry (Abdulkadir, 2012).

\subsection{Sampling Procedure}

The study used multi-stage sampling techniques. The first stage sampling involves the purposive sampling of three Local Government Areas; namely Ikara, Soba, and Zaria, based on intensity of residual soil moisture tomato cultivation. In the second stage, six villages were selected based on prevalence of residual soil moisture tomato cultivation. In the last stage, 210 residual soil moisture tomato farmers were randomly selected from the six (6) villages representing $5 \%$ of the total population of tomato farmers. The villages were identified with the help of Kaduna State Agricultural Development Project (KADP) extension agents.

\subsection{Method of Data Collection}

Primary were used for this study. The data was collected using the interview method with aid of structured questionnaires. The data was collected on socio-economic variables of the farmers, quantity and prices of inputs used and outputs realized. 


\subsection{Analytical Techniques}

Double Log production function analysis was used for the study. The implicit form of the double log production function is express as follows:

$$
\begin{array}{lr}
Y=F\left(X_{1}, X_{2}, X_{3}, X_{4}, X_{5}, \mu\right) & \text { equa } 1 \\
\log Y=\alpha+\beta_{1} \log X_{1}+\beta_{2} \log X_{2}+\beta_{3} \log X_{3}+\beta_{4} \log X_{4}+\beta_{5} \log X_{5}+\mu \quad \text {.equa } 2
\end{array}
$$

Where:

$\mathrm{Y} \quad=$ Yield of tomato $(\mathrm{kg})$,

a $\quad=$ Intercept,

$\beta_{1}-\beta_{5}=$ Parameters to be estimated

$\mathrm{X}_{1} \quad=$ Farm size (ha),

$\mathrm{X}_{2}=$ Quantity of Seed/seedlings $(\mathrm{kg} / \mathrm{ha})$,

$\mathrm{X}_{3}=$ Labour used (hour/man day),

$\mathrm{X}_{4} \quad=$ Chemical fertilizer $(\mathrm{kg} / \mathrm{ha})$

$\mathrm{X}_{5} \quad=$ Organic fertilizer $(\mathrm{kg} / \mathrm{ha})$,

$\mathrm{U}=$ Error term. (This is assumed to be normally distributed with mean, value zero and constant variance).

The resource use efficiency was computed as follows;

$$
\mathrm{r}=\mathrm{MVP} / \mathrm{MFC}
$$

equa 3

Where:

$\mathrm{r}=\quad$ Efficiency ratio

MVP = Marginal value product, which is the value of one unit of the product/produce

$\mathrm{MFC}=$ Marginal factor cost, which is the cost of one unit of a particular resource

The MVP was estimated as MVP $=\mathrm{MPPxi} \cdot \mathrm{P}_{\mathrm{Y}}$

$$
\text { MPP xi }=d y / d x i=\beta_{i} \bar{Y} / \bar{X}
$$

MPP xi = marginal physical product of a unit of input xi,

$\underline{\mathrm{P}_{\mathrm{Y}}}=$ price of output

$\overline{\mathrm{Y}}$ and $\mathrm{X}=$ mean values of the yield $(\mathrm{Y})$ and input $(\mathrm{X})$ respectively.

$\beta_{\mathrm{i}}=$ estimated regression coefficients.

The ratio $r$ was used to determine whether the resources are efficiently utilized, underutilized or over utilized.

The decision rule is:

If $\quad \mathrm{r}=1$ it implies that resources are efficiently utilized

$r>1$ implies that resources are under utilized

$\mathrm{r}<1$ implies that resources are over utilized

The value of the r-ratio determines whether the resources are efficiently utilized, underutilized or over utilized. The optimum level of output is achieved at a point where MVP = MFC. If $r=1$, it suggest that resources are not efficiently utilized. Adjustment is needed in the use of the input used and costs in the production process to restore to $r=1$.

\subsection{Determining Efficiency of Resource-use in Residual Soil Moisture Tomato Production}

The elasticity of production which is the percent change in output as a ratio of a percentage change in input was used to calculate the rate return to scale which is a measure of a firm's success in producing maximum outputs from a sets of input (Farrel, 1957).

$$
E P=\frac{M P P}{A P P}
$$

equa 4

Where;

$\mathrm{Ep}=$ elasticity of production

MPP =marginal physical product

APP $=$ average physical product

The decision rule is that if $\mathrm{EP}=1$ : constant return to scale, $\mathrm{EP}<1$ : decreasing return to scale and if EP > 1: increasing return to scale. 


\section{RESULTS AND DISCUSSION}

\subsection{Production Function Estimates}

The regression results revealed that $54.55 \%$ of the variability in tomato yield among the sample farms was explained by independent variables. This value is reasonably high given the obvious fact that there are other explanatory variables such as climatic changes and the managerial abilities of farmers which are indispensable for crop yields and were not considered in the model. The F-Value (43.969) was significant $(\mathrm{p}<0.01)$, implying that all the inputs used in tomato production jointly contribute to the output of tomato.

Table 1: Estimates of Cobb-Douglas production function for residual soil moisture tomato production

\begin{tabular}{llll}
\hline Variable & Coefficient & Standard Error & t-value \\
\hline Constant & 5.5758 & 1.6268 & $3.4275^{* * *}$ \\
Land $\left(\log X_{1}\right)$ & 0.2297 & 0.0835 & $2.7507^{* * *}$ \\
Seed/seedlings $\left(\log X_{1}\right)$ & 0.5638 & 0.2011 & $2.8035^{* * *}$ \\
Labour $(\operatorname{LogX})$ & 0.2783 & 0.1045 & $2.66^{* *}$ \\
Chemical fertilizer $\left(\log X_{1}\right)$ & 0.3395 & 0.1062 & 3.1963 \\
Organic fertilizer $\left(\log X_{1}\right)$ & 0.3437 & 0.1768 & 1.944 \\
$\mathrm{R}^{2}$ & 0.5455 & & \\
$\mathrm{R}$ & 0.5210 & & \\
$\mathrm{~F}$ & $43.967 * * *$ & & \\
$* \mathrm{P}<0.10, * * \mathrm{P}<0.05, * * * \mathrm{P}<0.01$ & & &
\end{tabular}

The positive signs of the coefficients indicated direct relationships between the inputs and output of Residual Moisture Tomato. Thus, a unit increases in the level of land, seed, labour, chemical and organic fertilizer will led to $0.22,0.56,0.27,0.32$ and 0.34 unit increase in tomato output respectively. The coefficients of land (0.229), seed (0.563), labour (0.278) and chemical fertilizer $(0.343)$ were significant $(\mathrm{P}<0.01)$, while that of organic fertilizer $(0.332)$ was significant $(\mathrm{P}<0.10)$. Similar finding was reported by Goni et al. (2013) in their study of dry season tomato production in Jere, Borno State, Nigeria.

\subsection{Elasticity of Production}

The elasticity of production measures the responsiveness of output to a change (increase or decrease) in input. Table 4 shows that $1 \%$ increase in the quantity of land, seed rate, labour, chemical fertilizer and organic fertilizer would led to the $0.229,0.564,0.278,0.323$ and 0.342 percent increase tomato. Moreover, the sum of elasticity is equal to 1.76 , implying that output (yield) increase by more than one percent if all inputs were increase by one percent. This suggests increasing return to scale in residual soil moisture tomato production. Hence, it pays to increase the quantity of inputs used in order to optimize the level of inputs used.

Table 2: Elasticity of Production and Return to Scale

\begin{tabular}{ll}
\hline Variable & Input Elasticity \\
\hline Land & 0.2297 \\
Seed/Seedlings & 0.5638 \\
Labour & 0.2783 \\
Chemical fertilizer & 0.3395 \\
Organic fertilizer & 0.3437 \\
Return to scale & 1.755 \\
\hline
\end{tabular}




\subsection{Resource Use Efficiency}

The result revealed that the ratios of seed, chemical and organic fertilizers were greater than unity, implying that these inputs were under-utilized. The reasons could be due to the high cost and scarcity of fertilizer. This suggests that tomato farmers could increase their output by increasing the level of these inputs. However, land and labour were over-utilized. This could be possibly due to low wage rate and predominant use of family labour.

Table 3: Efficiency of Resource-used in Residual Soil Moisture Tomato Production

\begin{tabular}{llll}
\hline Resources & MVP & MFC & R-ratio \\
\hline Land & 432.23 & 452.55 & 0.956 \\
Seed & 2860.218 & 300.00 & 9.535 \\
Labour & 37.628 & 62.00 & 0.607 \\
Organic fertilizer & 1809.218 & 800.00 & 2.262 \\
Chemical fertilizer & 714.856 & 60.00 & 11.914 \\
\hline
\end{tabular}

\section{CONCLUSION AND RECOMMENDATIONS}

The findings of this study revealed that the residual soil moisture tomato farmers were inefficient in the use of their seed, chemical fertilizer and organic fertilizers. This implies that those inputs were under-utilized in the course of their production. Similarly, they are operating at increasing return to scale; hence there is the need to expand the scope of their production by increasing the use of these inputs and achieve higher level resource-use efficiency. To achieve this there is the need to improve farmer's access to these inputs through effective and efficient extension service, easy access to formal credit facilities and also encourage them to form cooperative societies to enable them procure their inputs at reduce rate. These will ultimately aid them in expanding the scope their production and increased output.

\section{References}

[1] Abdulkadir, A.B. (2011). Economics of Residual Soil Moisture Tomato Production in Three Selected Local Gvernment Areas of Kaduna State, Nigeria. M.Sc. Thesis, Department of Agricultural Economics and Rural Sociology, Faculty of Agriculture, Ahmadu Bello University Zaria. Pp: 1- 65.

[2] Adenegan, K.O. and Adeoye, I.B. (2011). Price Analysis of Tomato Production in Rural and Urban Retail Markets of Oyo State, Nigeria. International Journal of Agricultural Economics and Rural Development. 4 (4): 90-96.

[3] FAO (2010). Production Year Book. Food and Agriculture Organization. Rome. Italy.

[4] Farrel, M.S. (1957). The measurement of productive efficiency. Journal of Royal Statistical Society Series, A (General) Part III Vol. 120.

[5] Goni, M., Umar, A.S.S. and Usman. S. (2013).Analysis of Resource-use Efficiency in Dry Season Vegetable Production in Jere, Borno State, Nigeria. Journal of Biology, Agriculture and Healthcare, 3(19): 18-23.

[6] Haruna, U., Sani, M. H., Danwanka, H. A. and Adejo, E. (2012). Economic Analysis of Fresh Tomato Marketers I Bauchi State, Nigeria. Nigerian Journal of Agriculture and Environment, 8 (3): $1-8$.

[7] Ibeke, U. C. and Adesope, O.M. (2010). Analysis of Dry Season Vegetable Production in Owerri West Local Government Area of Imo State, Nigeria, Report and Opinion, 2 912): 55-60. 
[8] Mbanasor, J.A. and Kalu, K.C. (2008). Economic Efficiency of Commercial Vegetable Production Systems in Akwa Ibom State, Nigeria. A Tran-slog Stochastic Frontier Cost Function Approach, Tropical and subtropical Agro ecosystems, 8: 313-318

[9] National Population Commission (2006). NPC Population Census of the Federal Republic of Nigeria. Census Report. National Population Commission, Abuja.

[10]Ojo, M.A., Ibrahim, O.A. and Mohemmed, U.S. (2009). Profitability and production Efficiency of Small-scale irrigated Tomato Production in Niger State, Nigeria. Continental Journal of Agricultural Economics. 3: 16-22.

[11] Tambo, J. A. and Theresa, G. (2010). Resource-use Efficiency in Tomato Production in the Dargne west District Ghana. Paper presented on Conference on international Research on Food Security, National Resource Management and Rural Development.

[12]Udo, E.J. (2005). Technical inefficiency in Vegetable Farms of Humid Region: An Analysis of Dry Season Farming by Urban Women in South-south Zone, Nigeria. Journal of Agriculture and Social Science, 1 (2):80-85.

[13]Usman, J. and Bakari, U.M. (2013). Profitability of Dry Season Tomato (Lysipersicom esculentum Mill) Production in Fufore Local Government Area of Adamawa State, Nigeria. International journal of Engineering and Science, 2 (11): 113-117. 